\title{
NSU
}

Florida

Nova Southeastern University

NOVA SOUTHEASTERN

UNIVERSITY

NSUWorks

HCBE Faculty Articles

H. Wayne Huizenga College of Business and

Entrepreneurship

6-2017

\section{An intersubjective perspective on the role of communal sharing in synergistic co-mentoring: Implications for Human Resource Development}

Bryan J. Deptula

Nova Southeastern University, bdeptula@nova.edu

Ethlyn A. Williams

Follow this and additional works at: https://nsuworks.nova.edu/hcbe_facarticles

Part of the Business Commons

\section{NSUWorks Citation}

Deptula, Bryan J. and Williams, Ethlyn A., "An intersubjective perspective on the role of communal sharing in synergistic comentoring: Implications for Human Resource Development" (2017). HCBE Faculty Articles. 588.

https://nsuworks.nova.edu/hcbe_facarticles/588 


\section{An Intersubjective Perspective on the Role of Communal Sharing in Synergistic Co-mentoring: Implications for Human Resource Development}

Bryan J. Deptula, Ethlyn Anne Williams

The present qualitative research provides an in-depth study of synergistic co-mentoring (SCoM) to understand its features and implications for HRM. We examine dyadic synergistic qualities and processes, and dyadic co-mentoring developmental qualities and processes that complement each other to make possible the emergence of SCoM. Using NVivo qualitative software, we analyzed interviews from a diversified sample of 26 matched mentoring dyads. Results demonstrate that communal sharing in the endeavor toward combinative outcomes complemented by co-mentoring supports intra-relational conditions for the emergence of SCoM.

Key Words: careers, co-mentoring, developmental relationships, synergy

Mentoring relationships are vitally important for both mentors and protégés in terms of objective career success (e.g., higher compensation, promotion rates, competency development) and subjective career success (e.g., feeling one's career was on or ahead of track) (Eby et al., 2013). Approximately 70\% of Fortune 500 companies employ mentoring programs as a form of HRD (Hegstad \& Wentling, 2004), and scholars suggest that everyone, from CEOs to first-line employees, needs a mentor (Clutterbuck, 2004).

Human resource development is defined as "the integrated use of (1) training and development, (2) career development, and (3) organization development to improve individual and organization effectiveness" (McLagan, 1989, p. 7). Limited research links mentoring and HRD (Hegstad, 1999); building this connection will be a critical point of transition for 
HRD professionals (HRDPs) to leverage mentoring as an approach to HRD (Thurston, D'Abate, \& Eddy, 2012). Yet few studies offer guidance on how to capitalize on dyadic developmental relationships in HRD initiatives for developing talent through proactive interactions, that is, interactions conducive to dyadic alliances that increase learning beyond what protégés or mentors could achieve in traditional mentoring (Clutterbuck, 1998).

Mentoring theory has not given much attention to the complexity of contemporary work arrangements (Garvey $\&$ Alred, 2001) or practical evolutions in developmental relationships such as collaboration and shared goal setting, which have received insufficient theoretical attention (D'Abate, Eddy, \& Tannenbaum, 2003). One exception is collaborative mentoring (co-mentoring), a "practitioner centered, experiential, ... reflective model used by peer co-mentors with the shared purpose to form "partnership support groups" that generate professional contributions (Mullen, 2000, p. 4). Observing a 17-member partnership support group, Mullen (2000) provided preliminary evidence of synergistic performance gains that might emerge when a group of individuals simultaneously collaborate on project-related tasks and professional development. However, the presentation of collaborative mentoring is theoretically underdeveloped; Mullen neither provides a definition of synergy or co-mentoring nor describes key features of the phenomenon. Further, grounded in the anecdotal reporting of partnership support groups in a single action research project in a university setting, co-mentoring suffers from a lack of understanding across contexts and does not address development at the dyadic level.

Irby (2012) intermingles synergistic mentoring with mentoring synergy. She defines synergistic mentoring as "a mentor and mentee working together collaboratively to (a) generate a greater good for both, (b) integrate diverse perspectives into the context, and (c) construct together an otherwise unattainable goal attempted independently" (Irby, 2012, p. 175). Given well-documented research that mentoring benefits both mentors and protégés (Eby et al., 2013), Irby's definition of synergistic mentoring lacks the precision to differentiate it from existing mentoring descriptions. Irby labels synergy as an aggregate abstract of trust, accommodation, and openness within paired relationships, but these concepts do not indicate synergy.

Synergy is an emergent phenomenon exhibited by groups when they "... accomplish collectively something that could not reasonably have been achieved by any simple combination of individual effort" (Larson, 2010, p. 4). Mullen (2000) found that partnership support groups generated more outputs in a shorter time than any member of the group could have independently produced, for example, 17 co-authored articles and conference presentations resulting from a yearlong interaction. Prior studies use myriad evidence of synergistic performance gains that are valuable in work contexts, showing that in comparison to a similar number of individuals working independently, two or more people interacting potentially propose solutions of higher complexity and solve problems more efficiently (Laughlin, Bonner, \& Miner, 2002), 
generate more-and higher quality_ideas (Cohen, Whitmyre, \& Funk, 1960), seek the highest value solutions (Larson, 2007), and make significantly more accurate collective judgments (Henry, 1993). Thus, group member interactions have synergistic potential. Because the emergent phenomenon of synergy is rooted in group interaction (Larson, 2010), within the setting of a dyad, interactive processes have the potential to realize synergistic gains.

Larson (2010) argues that within groups knowledge, skills, and abilities are important factors for producing synergy, and calls for research on members' qualities and the processes comprising observable or reported behaviors by group members performed in concert with one another. We suggest that task-focused interactions within a dyad have synergistic potential. Understanding how dyadic qualities and processes represent synergistic potential to produce synergy (combinative work outcomes) is needed in this field. Mullen and Lick (1999) hinted at the importance of group qualities in their anecdotal account of peers with different expertise (e.g., school administrators with local cultural knowledge, practitioners as living data sources, and university faculty as theory mentors) benefiting from a process of building on group members' diverse knowledge. The presence of certain qualities and processes, however, does not make performance gains an inevitable consequence of interacting in a mentoring relationship.

The purpose of the current study is to extend prior research on synergistic mentoring and co-mentoring by revealing the elements and features that comprise synergistic co-mentoring (SCoM) within dyads, and present a clear definition of SCoM to guide future research. The following research question drives our understanding of SCoM: What are the synergistic dyadic qualities and processes and developmental dyadic qualities and processes that characterize SCoM? We present an intersubjective perspective (Ickes \& Dugosh, 2000), by evaluating the alignment of dyad members' reported views of the relationship regarding the qualities and processes that define SCoM at the dyadic level. We use multiple sources of data to connect facts obtained from respondents' illustrative accounts of personal experiences in developmental relationshipsa novel approach seldom seen in HRD research (Rocco, 2003, 2010). Drawing from the literature on interactive processes (Ueno \& Adams, 2006), we describe dyadic qualities as involving members sharing complementarities including expertise, responsibility, and focus. Drawing from a process model of coordination (Bruns, 2013), we present processes as the combinations of actions between members within SCoM dyads, which include collaborative efforts. We examine synergistic properties that are present within the context of a co-mentoring dyad and propose a number of synergistic dyadic qualities and processes and developmental qualities and processes that complement each other to make possible the emergence of SCoM. We close by offering practical implications to help HRDPs understand how SCoM presents (a) opportunities to capitalize on the benefits of synergistic potential and the resulting synergy for career development and (b) a platform for mutual development (co-mentoring). 


\section{Background}

A mentoring relationship is one form of developmental relationship in which a more experienced mentor provides career and psychosocial support to a less experienced protégé (Cotton, Shen, \& Livne-Tarandach, 2011). Career functions enhance career development and include subfunctions such as career strategizing, challenging work/skill-building assignments, freedom and opportunity for skill development, coaching, sponsorship, job-related feedback, and information sharing. Psychosocial functions enhance individual competence, identity, and confidence in a professional role and include subfunctions such as counseling, friendship, personal feedback, role modeling, inspiration, and motivation.

Two important evolutions in mentoring research have caused a reconceptualization in the study of developmental relationships. First, Higgins and Kram (2001), and later Rock and Garavan (2006) put forward the idea of developmental networks: a protégés egocentric and dynamic constellation of individuals from career communities or nonwork contexts who offer personal and professional development such as career and psychosocial support. These studies opened exploration into the unique characteristics of various types of developmental relationships within a network. In addition to traditional mentors, protégés receive support from an array of individuals that "take an active interest in and action to advance the protégés career by providing developmental assistance" (Higgins \& Kram, 2001, p. 268). During developmental interactions, protégés may seek domain-specific expertise from coaches, job-specific skills from peer-mentors (Garvey, 2004), career mentoring from supervisors, technology support for older mentors from younger protégés in reverse-mentoring (Greengard, 2002), and role-based support from colleagues in a team-mentoring setting (Williams, Scandura, \& Gavin, 2009).

Second, in the search for understanding the unique dynamics of relationships that generate extraordinary career outcomes, scholars discovered important relational elements that distinguished high-quality relationships from traditional mentoring of marginal-quality and low-quality dysfunctional relationships (Ragins, 2016). A paradigmatic shift away from a focus on the traditional approach to mentoring, relational mentoring introduced a set of relational functions that become operant in addition to career and psychosocial support. Relational functions include a focus on both dyad members' personal learning and growth, inspiration, trust and commitment, shared influence and respect, self-affirmation, and reliance on communal norms (Ragins, 2012). Advancing theory on mentoring schemas, Ragins and Verbos (2007) argue that mentors and protégés apply preexisting psychological models to each developmental relationship. Cotton and Shen (2013), for example, rely on Fiske's (1992) theory of social relations to discuss the four models used by protégés to decipher how, and with whom, to initiate key developmental relationships when building their network. 
Fiske's (1992) theory of social relations details people's behavioral interactions in relationships, sorting of relationships, use of resources within relationships, and the frequency of interpersonal interaction. While Fiske presents four models of social relations (authority ranking, equality matching, market pricing, and communal sharing), we frame our analysis using communal sharing. When approaching relationships with a communal sharing model, the focus of social interaction among group members is based on equivalence structure-all members of a bounded unit are equivalent and treated the same, with members working collectively, contributing effort and ideas, and producing joint outcomes that transcend individual participants' capacities (Fiske, 1992). Communal sharing, with properties of symmetry and transitivity, and an emphasis on common purpose and mutual aid, enables members to work collaboratively until goals are achieved, gives every member equal access to group resources, and removes evaluation of individual members' inputs (Fiske \& Haslam, 2005). The study of social relations in developmental relationships is an important advancement in mentoring scholarship and has implications for understanding the connection between mentoring and the highly effective HRD strategy of using and embedding relationship-based talent development interventions in work contexts (Garavan, Carbery, \& Rock, 2012). However, Fiske's theory of social relations has been applied to neither understanding synergy or co-mentoring nor the practice of implementing mentoring initiatives for HRD. As we elaborate throughout the remainder of the study, we believe that the communal sharing model provides an intra-relational context for synergistic co-mentoring to emerge.

This review of the literature preceded data collection, provided us with key priorities for the research design, shaped our inquiry into developmental relationships, and helped us understand the context in which developmental relationships operate, which has changed as "work in organizations has become much more relational, interdependent, and collaborative in nature" (Parise, 2007, p. 360). Building on the above developments, we examine the role of a highquality focal mentorship within the developmental network characterized by synergy, co-mentoring, and dyad members' communal approach to social relations.

\section{Methods}

Heeding calls for richly contextualized accounts of developmental relationships in the 21 st century (Eby et al., 2013), we employed a qualitative methodology to build concepts and to understand relationships among phenomenon (Merriam, 2009).

\section{Context and Sample Selection}

We employed a phenomenological approach to our research (Corbin $\&$ Strauss, 2014), studying information-rich cases. To participate in the study, respondents were required to be currently engaged in a developmental relationship with a mentor or protégé, who would also participate in the study. Our purposive 
target sample comprised 26 dyads, including 5 dyads from a national hotel chain and 21 dyads originating from an executive MBA program at a university in the southeastern United States. While interviews with executive MBAs took place in a university setting, their matched dyad partners were not enrolled in the program. All relationships reported by respondents took place in organizational settings, and respondents represented numerous organizations, industries, areas of expertise, and hierarchical positions. Ninety-eight percent of respondents were employed full time at the time of data collection. See Table 1.

\section{Data Collection Procedure}

A three-person research team collaborated in designing the research protocol, while two researchers conducted interviews. We provide sample interview questions in Table 2. We opted for a semistructured interview format, using open-ended questions. Interviews lasted about 45 minutes, were audiotaped, and transcribed. Using the principle of theoretical sampling to guide our decisions regarding data sufficiency, data collection stopped when we judged that further data collection would not add incremental value to the discovery process, indicating that our data achieved theoretical saturation (Robinson, 2014).

\section{Data Analysis}

Stage 1: First-Order Coding Employing NVivo 10 qualitative software, we began by segmenting each respondent's answer to each interview question. Two researchers acted as coders, were given a set of interviews to analyze, and later checked for coding agreement. We used open coding (Merriam, 2009), highlighting any data fragment (i.e., sentence or theme) of analytic value. The team met to create formulated meanings, which are statements constructed by researchers to describe fragments. Using axial coding, we identified elements that are common themes among grouped data fragments. We agreed upon a master list of codes, which constituted our codebook, then iteratively disaggregated and categorized all emergent themes into characteristics of developmental interaction constructs.

Stage 2: Identifying Themes and Features of SCoM Next, we used constant comparative methodology, the process of identifying themes within our data that did not fit with existing descriptions of developmental interaction constructs (Corbin \& Strauss, 2014). In so doing, we discovered the elements and features (groups of elements) of SCoM and organized them according to (a) synergistic dyadic qualities and processes, and (b) developmental dyadic qualities and processes:

1. Synergistic dyadic qualities include expertise complementarity, coalition goal responsibility, and outcome focus.

2. Co-mentoring dyadic qualities include expert level knowledge, mutual support, and inducibility (the willingness of individuals to shape and be shaped by one's partners' thoughts; Deutsch, 2003). 


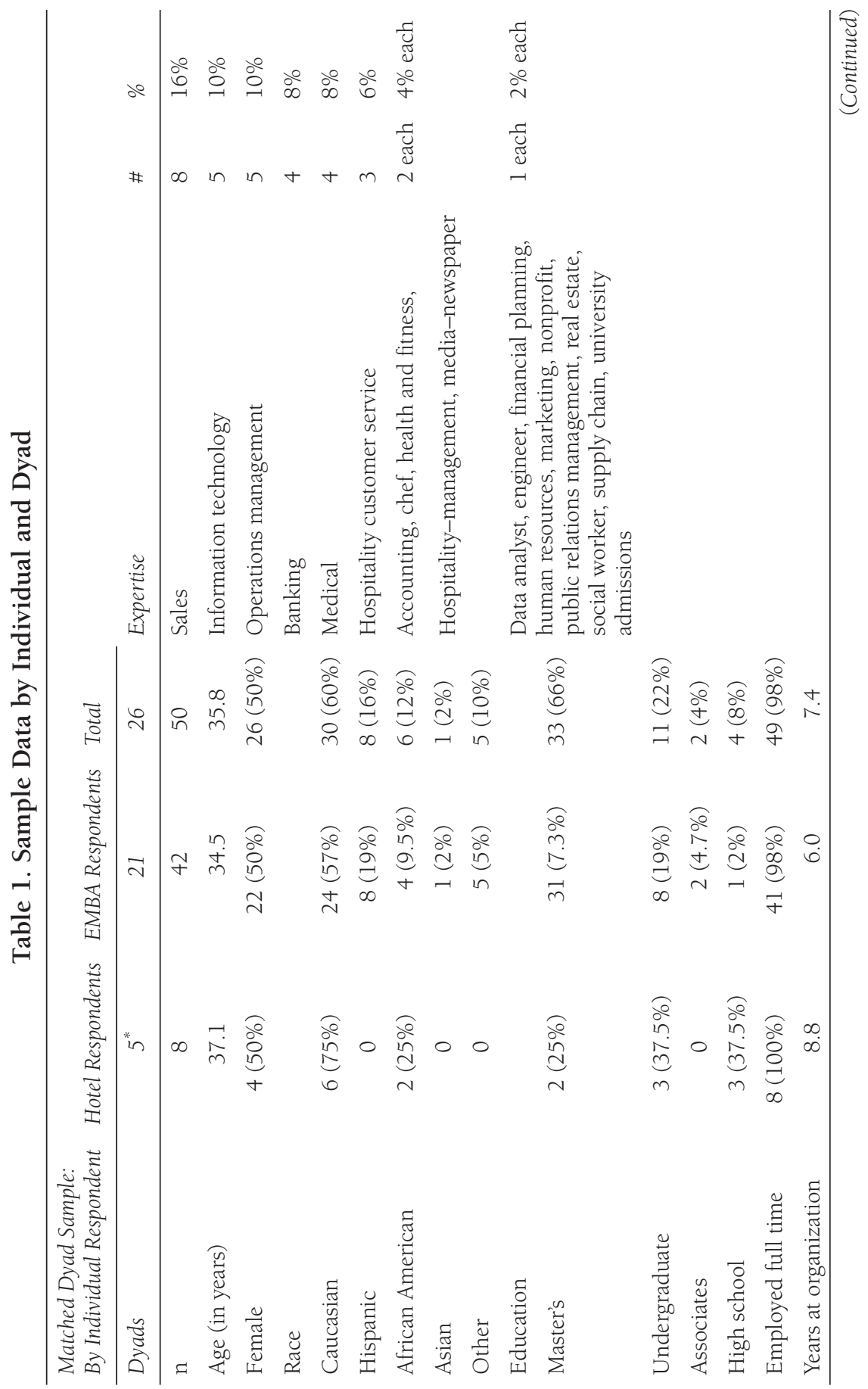




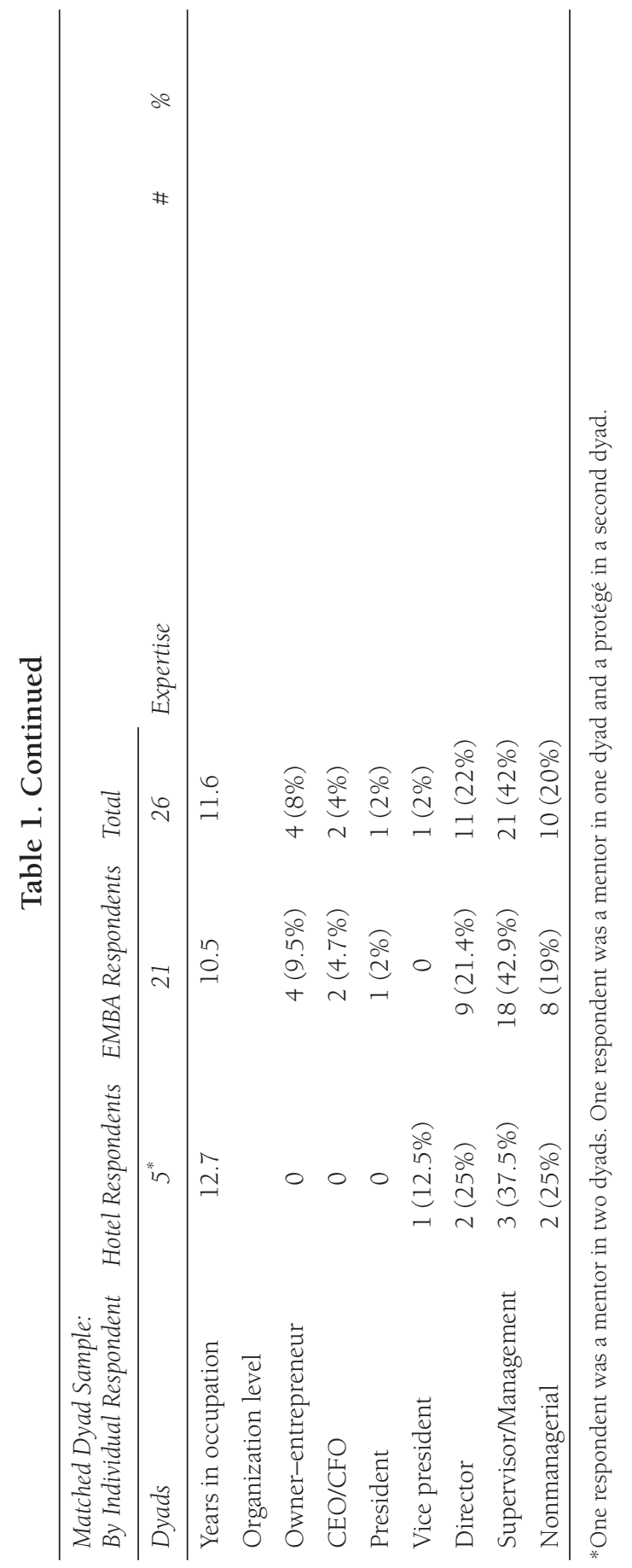


3. Synergistic dyadic processes include role inversion (the member with greater domain-specific expertise leads development), collaboration and coordination, and distributed rewards (shared credit and benefits from accomplishments).

4. Co-mentoring dyadic processes include fluid expertise, collaborative development, and knowledge generation.

We recognized that qualities and processes were effectively inert features that, only when operationally combined with one another, made it possible for the domains of SCoM to emerge. This classification recognizes features of career-focused developmental relationships that indicate SCoM is an integration of four qualities and processes that generate outcomes greater than the sum of their parts. Next, we classified features into theoretically distinct domains-dyadic synergistic characteristics and dyadic co-mentoring characteristics - and aligned the domains with two HRD imperatives: training and development with dyadic co-mentoring characteristics, and career development with both synergistic dyadic characteristics and dyadic co-mentoring characteristics. Table 2 describes the data analysis process.

Comparing Qualities, Processes, and Intersubjective Alignment of Each Dyad The research team used consensus decision making to categorize 8 of the 26 dyads as SCoM. We agreed that, to be categorized as a SCoM dyad, a dyad must meet the following criteria: (1) All four qualities and processes of synergy and co-mentoring had to be present within the dyad's data; and (2) dyad members achieved intersubjective alignment, wherein both dyad members expressed parallel descriptive statements regarding the synergistic and comentoring domains. In contrast, the 18 non-SCoM dyads either did not describe all four qualities and processes or did not achieve intersubjective alignment. In the findings reported below, while all SCoM dyads presented all four qualities and processes of synergy and co-mentoring, we report only the most prominent and representative statements that illustrate synergy and co-mentoring domains of SCoM. To present a parsimonious presentation of our findings, each dyadic quality discussed below is paired with the dominant process we found in analyzing interviewee reports that enabled the realization of synergy and/or comentoring. Table 3 offers data comparing SCoM and non-SCoM dyads.

\section{Findings: Describing Features of Synergistic Co-mentoring}

In the following sections, we present our findings and offer support for Synergistic Co-mentoring.

\section{Synergistic Qualities and Processes}

Synergistic characteristics in SCoM take shape in dyads when members combine qualities of expertise complementarity, coalition goal responsibility, and outcome focus in tandem with processes of role inversion, collaboration and coordination, and distributed rewards. The SCoM approach is 
Table 2. Diagram of Data Analysis and Coding

Career Development

Training \& Development

Situating domains within HRD imperatives

\section{Dyadic Synergistic Characteristics:}

Potential to accomplish joint outcomes exceeding individual achievement potential

\section{Dyadic Co-Mentoring Characteristics:}

Potential for direct mutual influence

Labeling domains

\begin{tabular}{|c|c|c|c|}
\hline Dyadic Qualities & Processes & Dyadic Qualities & Processes \\
\hline $\begin{array}{l}\text { - Expertise comple- } \\
\text { mentarity }\end{array}$ & - Role inversion & $\begin{array}{l}\text { - Expert level } \\
\text { knowledge }\end{array}$ & - Fluid expertise \\
\hline $\begin{array}{l}\text { - Coalition goal } \\
\text { responsibility }\end{array}$ & $\begin{array}{l}\text { - Collaboration } \\
\& \text { coordination }\end{array}$ & - Mutual support & $\begin{array}{l}\text { - Collaborative } \\
\text { Development }\end{array}$ \\
\hline - Outcome focus & $\begin{array}{l}\text { - } \begin{array}{l}\text { Distributed } \\
\text { rewards }\end{array}\end{array}$ & - Inducibility & $\begin{array}{l}\text { - Knowledge } \\
\text { generation }\end{array}$ \\
\hline
\end{tabular}

Identifying data fragments (elements) and themes (features) within coded data

- What role does the mentor/protégé play?

- How do you see the future of this relationship (how will it evolve, continue to develop)?

- What have been the outcomes of the relationship for you and your partner? What goals are met?

- Describe the quality of the relationship.

- Compared to your prior or current mentorships, give examples of how is this one similar or different?
- How does learning occur within the relationship?

- What needs does the relationship fulfill?

- Has the relationship helped your career or development?

- What activities are done together?

- In what settings do you meet?

Discovery began by creating the above sample interview protocol items

dyad-centric and extends beyond established mentoring support functions by approaching development through communal sharing, allowing both dyad members to realize synergistic potential. Respondent Brad (\#4) shared: "Alone, I would not have been able to accomplish what we have done so far for the company."

Expertise Complementarity and Role Inversion Faraj and Sproull (2000) define expertise as "specialized skills and knowledge that people bring to the team's task" (p. 1555). Expertise facilitates the potential to convert knowledge into a useable resource across contexts and intra-relational roles (i.e., externalization). Fusaroli, Raczaszek-Leonardi, and Tylén (2014) found that complementarity, defined as the way people doing different things come to form a coherent whole, led to interpersonal synergy when structures initiated by one 
Table 3. Comparison Table of SCoM Dyads Versus "Other"

\begin{tabular}{|c|c|c|c|}
\hline Dyad Characteristics & $\begin{array}{l}\text { SCoM } \\
(n=8)\end{array}$ & $\begin{array}{l}\text { Other } \\
(n=18)\end{array}$ & Total \\
\hline \multicolumn{4}{|l|}{ Age (avg. years) } \\
\hline \multirow[t]{2}{*}{ Mentor } & 43.5 & 36.8 & 38.9 \\
\hline & $(\min =31, \max =60)$ & $(\min =27, \max =56)$ & $(\min =27, \max =60)$ \\
\hline \multirow[t]{2}{*}{ Protégé } & 36.25 & 31.7 & 33.1 \\
\hline & $(\min =28, \max =47)$ & $(\min =24, \max =44)$ & $(\min =21, \max =47)$ \\
\hline \multirow[t]{2}{*}{ Age difference } & 7.75 & 6.2 & 6.7 \\
\hline & $(\min =1, \max =14)$ & $(\min =0, \max =18)$ & $(\min =0, \max =18)$ \\
\hline \multicolumn{4}{|l|}{ Gender } \\
\hline Different gender & $1(12.5 \%)$ & $7(38.9 \%)$ & $8(30.8 \%)$ \\
\hline Same gender & $7(87.5 \%)$ & $11(61.1 \%)$ & $18(69.2 \%)$ \\
\hline \multicolumn{4}{|l|}{ Education } \\
\hline $\begin{array}{l}\text { Mentor has higher } \\
\text { education }\end{array}$ & 0 & $7(38.8 \%)$ & $7(27 \%)$ \\
\hline $\begin{array}{l}\text { Protégé has higher } \\
\text { level of education }\end{array}$ & $3(37.5 \%)$ & $3(16.7 \%)$ & $6(23.1 \%)$ \\
\hline $\begin{array}{l}\text { Same level of } \\
\text { education }\end{array}$ & $5(62.5 \%)$ & $8(44.4 \%)$ & $13(50 \%)$ \\
\hline \multicolumn{4}{|l|}{ Race } \\
\hline Different ethnicity & $4(50 \%)$ & $8(44.4 \%)$ & $12(46.2 \%)$ \\
\hline Same race & $4(50 \%)$ & $10(55.6 \%)$ & $14(53.8 \%)$ \\
\hline \multicolumn{4}{|l|}{ Formal vs. informal } \\
\hline Formal & $1(12.5 \%)$ & $3(16.7 \%)$ & $4(15.4 \%)$ \\
\hline Informal & $7(87.5 \%)$ & $15(83.3 \%)$ & $22(84.6 \%)$ \\
\hline \multicolumn{4}{|l|}{$\begin{array}{l}\text { Reporting } \\
\text { relationship (at } \\
\text { initiation) }\end{array}$} \\
\hline Supervisory & $2(25 \%)$ & $11(61.1 \%)$ & $13(50 \%)$ \\
\hline Nonsupervisory & $3(37.5 \%)$ & $7(38.8 \%)$ & $10(38.5 \%)$ \\
\hline Peer & $3(37.5 \%)$ & 0 & $3(11.5 \%)$ \\
\hline \multicolumn{4}{|l|}{$\begin{array}{l}\text { Relationship length } \\
\text { (years) }\end{array}$} \\
\hline Mean & 7.25 & 4.1 & 5.1 \\
\hline Minimum & 0.5 & 0.5 & 0.5 \\
\hline Maximum & 20 & 16 & 20 \\
\hline
\end{tabular}


Table 3. Continued

\begin{tabular}{|c|c|c|c|}
\hline Dyad Characteristics & $\begin{array}{l}\text { SCoM } \\
(n=8)\end{array}$ & $\begin{array}{l}\text { Other } \\
(n=18)\end{array}$ & Total \\
\hline \multicolumn{4}{|l|}{$\begin{array}{l}\text { Organizational } \\
\text { distance (at } \\
\text { initiation) }\end{array}$} \\
\hline Mentor higher up & $6(75 \%)$ & $16(88.9 \%)$ & $22(84.6 \%)$ \\
\hline Parallel & $2(25 \%)$ & $2(11.1 \%)$ & $4(15.4 \%)$ \\
\hline \multicolumn{4}{|l|}{$\begin{array}{l}\text { Organization } \\
\text { bounded (at time of } \\
\text { interview) }\end{array}$} \\
\hline $\begin{array}{l}\text { Still at same org- } \\
\text { no change }\end{array}$ & $3(37.5 \%)$ & $12(66.7 \%)$ & $15(57.7 \%)$ \\
\hline $\begin{array}{l}\text { Changed org but } \\
\text { maintained } \\
\text { relationship }\end{array}$ & $5(62.5 \%)$ & $6(33.3 \%)$ & $11(42.3 \%)$ \\
\hline \multicolumn{4}{|l|}{$\begin{array}{l}\text { Years in occupation } \\
\text { (avg.) }\end{array}$} \\
\hline \multirow[t]{2}{*}{ Mentor } & 15 & 6.7 & 13.1 \\
\hline & $(\min =4, \max =40)$ & $(\min =2, \max =20)$ & $(\min =2 \max =40)$ \\
\hline \multirow[t]{2}{*}{ Protégé } & 9.1 & 11.5 & 8 \\
\hline & $(\min =.2, \max =20)$ & $(\min =2, \max =25)$ & $(\min =.2, \max =25)$ \\
\hline \multicolumn{4}{|l|}{$\begin{array}{l}\text { Years at } \\
\text { organization (at } \\
\text { time of initiation, } \\
\text { avg.) }\end{array}$} \\
\hline \multirow[t]{2}{*}{ Mentor } & 3.5 & 10.6 & 8 \\
\hline & $(\min =1, \max =5.5)$ & $(\min =1, \max =27)$ & $(\min =1 \max =27)$ \\
\hline \multirow[t]{2}{*}{ Protégé } & 4.1 & 5.36 & 4.7 \\
\hline & $(\min =.5, \max =9)$ & $\begin{array}{l}(\min =.5 \\
\max =12.5)\end{array}$ & $\begin{array}{l}(\min =.5, \\
\max =12.5)\end{array}$ \\
\hline
\end{tabular}

dyad member were finished by the other. Data revealed dyad members' expertise complementarity, referring to the quality that each dyad member possessed domain-specific expertise that gave rise to joint actions with mutually positive outcomes. Our findings regarding expertise complementarity within SCoM dyads align with Bunderson and Sutcliffe's (2002) finding that diversity in functional experience and practice within management teams signified nonoverlapping knowledge and expertise, which increased information and unit performance. Non-SCoM dyads did not display synergistic features and used unidirectional knowledge transfer. 
We took a week vacation to study together. That's where the true bond was formed. We got to know each other personally and professionally. She's very technical; I am not. She helped me understand technical concepts. She's great with people but doesn't like chitchat. That is where I am strong-building relationships. We were a great complement to one another. (Tara, \#1)

Expertise complementarity is illustrated in the shared pool of skill resources to draw from, at times compensating for individual shortcomings and building upon individual strengths. Dyad members reported identifying each other as a potential teammate, someone who brought an expert skill level that would help overcome weaknesses in a specific performance competency when acting as a team.

We have worked together (on a team), so we bounced ideas off of each other. There were areas that she had strengths in and I had weaknesses in. We bonded to each other, and that helped develop her weaknesses and my weaknesses as well... So that definitely helped my competency, allowing me to perform my job better. (Kelly, \#8)

Although some dyads were initiated within the same organization, none of the dyads we identified as possessing synergistic potential combined members with the same functional area of expertise. In dyad $\# 2$, for example, synergistic work efforts preceded mentoring with Brandon, who recognized synergistic potential with Matthew, a consultant at the time of relational initiation, that provided financial expertise that was lacking in the organization.

He got involved in the accounting side of the business when I needed him and he eventually became CFO. Matthew would always come in and we sat down to talk about things. He impressed me as being a person who was a problem solver. Our relationship was an integral part of the reason why that bank was successful for all the years it was. So it reinforced to me the decision I had made to bring in an expert. (Brandon, \#2)

Acting on expertise complementarity made synergy possible and allowed members to achieve performance gains they could not have achieved independently. Kate (\#5) discusses below how having multiple bases for interaction increased visibility of dyad member Lauren's equally important, yet distinct and complementary, areas of knowledge and expertise.

We participate in a lot of similar meetings together because we work on similar project teams. Lauren came from another company, so I was asked to support her, get her involved in the process, and help her understand the business. She came from a human resources background. I know process and she knows people. I asked if she would spend time coaching me based on her HR experience. 
She said, "Let us see how we can work together to figure out our challenges and possible change so our departments could work better together." (Kate, \#5)

Synergistic potential becomes synergy realized when reflexive role inversion becomes operant in conjunction with expertise complementarity. In collaborative contexts, role inversion occurs when the member with greater domainspecific expertise leads the process of ideas and knowledge generation, and becomes the focal point of contact for all problem solving, coordination, and goal accomplishment (Sherman, 2002). We found role inversion to be present when both members were in possession of information related to mutual goals, perceived each other as teammates, and felt secure because of individual accountability for the dyad's goals. The quote below exposes how SCoM goes beyond mentoring support functions discussed in the literature. Sadie (\#7) exemplified role inversion in action when someone outside the dyad sought information from a dyad member who was unavailable.

People know they can go to either of us because we share 90\% day-to-day responsibilities. The answer she would give would almost always be the same answer I would give. It makes me feel very secure knowing I can do a good job because I have her as my teammate. (Sadie, \#7)

\section{Coalition Goal Responsibility and Collaboration and Coordina-} tion A distinguishing quality of synergistic potential in interviewee reports is that when realizing synergy, members act as a coalition: "alliances of members uniting to achieve a common objective" (Stevenson, Pearce, \& Porter, 1985, p. 267). Sadie and Zoe (\#7) exemplify our results in their description of synergistic efforts, operating as a unit on a project where the dyad was empowered with start-to-finish responsibility for achieving objectives:

We were given a project to open a new center-a huge responsibility given to us because of our relationship and how well we work because we share the same vision and beliefs. We share common goals, work together, and accomplish them. I needed a go-to person. ... I took her under my wing to guide her into meeting her goals, and I needed someone with her knowledge and expertise to meet my goals. My job would be much harder without her. We feed off, and teach, each other. With her it's a team approach. (Sadie, \#7)

Organizationally, we come across as a united front. We work really well together. If she gives me something, I want to give her something back because it is a mutual relationship. We show employees we're on the same page, meeting organizational goals. (Zoe, \#7)

Members capitalized on the benefits of synergistic potential by using a coalition approach to grow their individual achievements. Accordingly, 
members strategically planned how to join efforts to mutually help one another. Carly (\#3) explains: "We work on projects together and attend conferences, trainings, and social networking events."

To achieve synergy based on synergistic potential required a collaborative process approach to developmental relationships between individuals with diverse and complementary expertise who coordinated to achieve mutually beneficial goals. Collaboration is a process of interactive behaviors between dyad members with diversely specialized expertise that is compulsory for accomplishing tasks requiring unique types of knowledge that one party could not develop alone (Cummings \& Kiesler, 2007). Our data suggest that the guiding principle of collaborative behaviors was the achievement of each partner's developmental goals and career objectives, and/or goals specifically tied to the dyad as a unit responsible for producing outcomes. Kelly (\#8) elaborates: "Dana doesn't come to me as meeting a mentor, but like a team working collaboration. Because it's a team goal, we work together to achieve that goal."

Synergistic characteristics were manifested in coordinating activities, that is, the "ongoing accomplishment of managing interdependencies in collective work" (Bruns, 2013, p. 63). Fusaroli et al. (2014) found that successful complementary coordination predicted synergy when people doing different things in a system form a higher level integrated structure. Tara (\#1) describes: "We shared a territory, client base, and commissions. We worked together on everything from scheduling to looking at an individual client's situation and collaborating to find the best solution for them." Coordination is pivotal for integrating the diverse contributions of each dyad member, where cross-domain collaboration fostered innovation and knowledge development (Bruns, 2013).

We literally shared calendars and assisted each other. If I had been in one place, she was in another place. We would rotate. She has given that back to me. I have just as much an effect on her as she does on me. Sometimes she'll say more so. When she was working for my company, we presented seminars together, basically a tag team effort. We did our marketing efforts together; both of our names and pictures were on everything. There was a lot that we were actually partners. (Emily, \#1)

Outcome Focus and Distributed Rewards This highlights the importance of realizing synergistic potential to produce synergy in the HRD processcombinative efforts resulting in synergy deliver individual career achievements and development for both dyad members. This differs from the focus of non-SCoM dyads that we studied; in non-SCoM dyads, focus is almost exclusively on producing individual-level and protégé-centric outcomes. Prior research suggests that protégé-centric relationships involve a primary focus on the mentor's ability to influence the protégé's career development (Eby et al., 
2013); effectively, protégés rely on the mentor's resources to help the protégés achieve their goals. SCoM extends mentoring theory by illustrating how joint efforts on projects and objectives, using both members' resources (e.g., knowledge, skills, abilities), leads to synergistic professional achievements and career growth for dyad members. Dana (\#8) notes how a focus on outcomes fostered shared recognition and distribution of rewards from individual and collective achievements generated from the use of pooled resources:

I'm Kelly's partner. I overlap her territory. We talk about the physicians in her territory, what they're doing, discuss numbers. It's different when you're working with a peer rather than in a training situation. She brought me into their offices because she was already calling on them. She introduced me to them and helped me build my relationship with them. We really help each other out a lot within the job and we try to grow business together now; it's not one-sided in any way. So it's now a formal partnership. (Dana, \#8)

Emphasizing Communal Sharing Through Joint Tasks The synergistic qualities and processes discussed above reveal that communal sharing appears to be the predominant approach taken by SCoM dyads in our data. In communal sharing, individuals freely offer their resources to the group to achieve collective goals, and every member's talents are valued and contribute toward the group's objectives. As we illustrated with quotes above, the major differentiating factor between SCoM and non-SCoM dyads is that SCoM dyad members had expertise complementarity, engaged in role inversion, and participated in coalition work that employed shared responsibility and collaboration and coordination to accomplish objectives the dyad was responsible for producing. Communal sharing rests heavily on a sense of distributive justice (fairness in distribution of rewards), where the combined resources of the dyad are shared without regard to individual usage (Fiske, 1992). SCoM dyads focused on producing outcomes that were made possible through the distributed rewards.

\section{Co-mentoring Qualities and Processes}

Co-mentoring characteristics indicate potential for mutual direct influence in development. The SCoM approach extends beyond established co-mentoring literature by suggesting specific qualities and processes involved in collaborative development with mutual support and commitment. Our description of co-mentoring in SCoM highlights that both dyad members possess and share expert-level knowledge through fluid expertise and provide mutual support through collaborative development, and that inducibility facilitates knowledge generation.

Expert-Level Knowledge and Fluid Expertise In identifying unique characteristics of SCoM, we found that for co-mentoring potential to exist, both members must achieve expert-level knowledge. Chase and Simon (1973) 
posit individuals develop expert-level knowledge over a minimum 10 years of learning through practice in a particular occupation. In our sample of SCoM dyads, the number of years both mentors (15 years) and protégés (9.1 years) spent in their respective occupations indicated, by proxy, that they likely achieved expert-level knowledge.

Interviews revealed that co-mentoring occurs in a dynamic context for reciprocal growth, in which role incumbents abdicated hierarchical mentorprotégé roles to reap the benefits of fluid expertise (Fletcher \& Ragins, 2007). The types of exchanges described below were made possible through the fluid or boundary-crossing activity of shifting across expert to nonexpert intra-relational roles within a dyad, known as the process of fluid expertise (Ragins, 2012). Because members considered each other experts, they had not given much thought to making a distinction among hierarchically structured roles of mentor and protégé. Tara (\#1): "We never formally established which one of us was going to be mentor or mentee." Matthew (\#2): "I do not know that we ever, until this research opportunity came up, used the word mentor between us." Brad (\#4): "We never said, "You are the mentor and I am a protégé."'

So integrated were the roles in some dyads, members were unable to tell who was developing whom at any given time. We illustrate the following question and answer between the researcher and respondent: Kate (\#5): Q: "Are you Lauren's mentor? Or is she your mentor?" A: "I go back and forth ... it started off maybe as she was my mentor. Now, I think that we built the relationship that we often mentor each other."

The implication of both members having expert-level knowledge is that each situation dictated which member was responsible for driving development within the dyad, where the member with superior expertise-level knowledge assumed the lead developmental role (Fletcher \& Ragins, 2007). When both dyad members were experts, as opposed to having one novice protégé and one expert mentor, development became the collective responsibility of the dyad.

We bounced ideas off each other, so there were things like a selling strategy or best demonstrative practice that she did that I didn't know about. We would go in to one office she would observe me do a sales call and give me feedback. And the next one I would have her do it and then I would provide a feedback for her. It made me a better salesperson. (Kelly, \#8)

Sharing the task of development effectively removed the developmental burden on a single member, creating an intra-relational context conducive to shared opportunities for exchange of expertise. Shared responsibility contributed value toward meeting each dyad member's idiosyncratic developmental needs.

Mutual Support Through Collaborative Development Interviewee responses highlighted that co-mentoring involved mutual support, as 
suggested in the definition of co-mentoring (Mullen, 2000). Collaborative development is also implied in the definition of co-mentoring. Our interviews suggest that this involves the mutual provision of multiple career and psychosocial support functions and that both dyad members enjoyed nonhierarchical role status. While the definition of co-mentoring in the literature is imprecise, we suggest that in SCoM mutual support is made possible through a process of collaborative development, which provides a relational context within SCoM dyads where both members were able—and felt compelled-to offer career and psychosocial support functions. Several elements of the following quote illustrate mutual support through collaborative development through mutuality in provision of numerous career and psychosocial support subfunctions:

I kept opening opportunities for him within the organization exposing him to various people, all people within the organization and different areas of the bank and then discussed them openly with him. I gave him guidance on how to possibly approach problem solving in different areas, and he kept excelling like a very few that I have seen. Conversely, I call him if anything is on my mind, for example, if it relates to those recent regulatory exams we're going through or for a personal matter-we're friends. (Brandon, \#2)

Co-development is implied insofar as we're going through indicates that both individuals are concurrently sharing the experience of regulatory exams, supporting each other's careers, and playing a part in one another's personal lives by providing an abundance of support functions. Matthew (\#2) illustrates the power of both members offering career advancement opportunities, providing support in conjunction with a dyad member (as opposed to for a protégé).

I would think that both of us are going to continue to benefit from it at different times and different ways, and it's ultimately going to be best he would want to include me in some way; and if I'm able to make a success in something, I know I will include him. (Matthew, \#2)

Brandon (\#2) confirms Mathew's sentiments, imparting that members in SCoM engage in mutual support regardless of contextual boundaries or career aspirations: "If I had an investor group that wanted to start a community bank, Matthew would be one of the first people I call to the executive management team. That's how much I would trust him."

Being able to offer mutual support allowed dyad members to prepare one another for increasingly challenging roles:

I'll come to her and say, "I'm going to this meeting, they need some people willing to do this or that—are you interested? Is it something I could put your name in 
there?" She will do the same for me. She started encouraging her management team, saying, "Kate added a lot of value to our department. It would be a great opportunity if we could find something for her." When a position opened, she vouched for me. Now I'm here managing a big team. A lot had to do with her helping me and overall the things I've learned in the past year from her. (Kate \#5)

Inducibility and Knowledge Generation Inducibility refers to the willingness of individuals to shape and allow their thoughts and thought processes to be shaped by a psychologically close individual (Deutsch, 2003) and is an individual psychological foundation for creating the dyadic quality of transactive memory (Wegner, Giuliano, \& Hertel, 1985). Transactive memory is an emergent phenomenon in groups that refers to the interconnectedness of partners' thoughts that helps them connect knowledge independently held by each member to create higher level knowledge. Transactive memory indicates that members "think about things in ways they would not alone" (Wegner et al., 1985 , p. 254). Carly (\#3) illustrates inducibility: "I look forward to what she brings to her inquiry. She looks at things with a fresh pair of eyes and does not always accept things as they are. That helped me see a different perspective."

In SCoM dyads, member inducibility was manifested through a process of knowledge generation, through which knowledge entered and was stored and organized within SCoM dyads. Members informed us that they proactively considered each other's thoughts by sharing higher and lower order information.

Even if she did not agree with what I had to say ... if she had a way of thinking or had an idea or a decision made in her head, she still gave me the opportunity to counter her argument, listen to me, and take that into consideration. (Sadie, \#7)

Mason (\#6) shows how dyad members cogitated on what they could learn from the situation: "Learning takes place purely informally. I pop up an article and we sit down and discuss ideas. Working together, we figured things out." Russell (\#6) confirms the process of knowledge generation within the dyad: "Mason owns his company. We no longer work for the same organization. He asked what I thought of situations. I started bouncing ideas off him."

Members jointly experienced an event, coded the information in their individual memories, and subsequently reflected on what each member thought, developing integrated knowledge and memory that was useful to the dyadic unit.

Since we were both licensed, we do idea sharing, brainstorm about products and what's best for clients. We've recognized my strengths are product knowledge and I follow the markets like crazy. She'll call me and say, "I got this client-here's the situation. What do you think about this product? What do you think, shall we do 
this?" Her strength is definitely being a people person and networking. I'll call her and ask, "Hey, look at the market. What do you think we should do about these clients? What should I say to this person?" It is satisfying to me to be able to fulfill her gaps and that mine are being fulfilled. (Emily, \#1).

Emphasizing Communal Sharing Through Reciprocal Exchange Per the theory of interpersonal relations, communal sharing manifests when members freely give to, and take from, pooled resources (Fiske \& Haslam, 2005). Respondents revealed that by creating structures for coordinating developmental interactions, collaborative endeavors bolstered solidarity and led to dyadic achievements that resulted in individual career achievement and employee development. This highlights the importance of co-mentoring in the HRD process. Our research suggests that collaborative development is critical for integrating the diverse contributions of individuals with specialized and tacit knowledge in developmental relationships, but difficult to achieve when equality-based exchange norms are present within the dyad and there is a focus on protégé-centric outcomes. We found examples of reciprocal exchange in co-mentoring (shown above), where the mutual provision and receipt of developmental support was not contingent on individual contributions. SCoM extends mentoring theory by illustrating how dyad members offered a range of support without expectation of reciprocity, wanting only to improve the career of the other dyad member, leading to employee and career development.

\section{Predominant Model of Communal Sharing and Definition of SCoM}

We next conducted analyses to understand the intra-relational context that makes SCoM possible, comparing respondents' statements to the facets of social interaction that represent each schematic model people use to construct relationships (Fiske, 1992). This revealed that the qualities of SCoM highlighted in our data closely aligned to the communal sharing model. Below, we further elaborate on the features of communal sharing that we found in our data, and how communal sharing creates an intra-relational context conducive to the emergence of SCoM.

Significance of Time Collaboration within SCoM relationships may extend over time and across personal and professional contexts; this conveys the importance of the significance of time with respect to communal sharing.

The relationship lasted inside the same organization for over a year and a half. For eight and a half years outside the original organization where we met we've maintained the relationship. I see us still being friends. I'm still depending on his advice. (Russell, \#6)

Not only did respondents provide descriptive accounts of long-standing relationships involving collaborations across time and contexts, the average 
length of SCoM dyads was over 7.25 years versus 4.1 years for non-SCoM dyads (see Table 3). A long-standing collaboration forms when members jointly pursue shared goals and projects, and this emergent relational property manifests when members continually reinvest more of themselves into, and derive utility from, the relationship over time. Consistent with the communal sharing model, members derived a portion of their identity from this, one of their closest and most enduring personal relationships (Fiske \& Haslam, 2005). Amber (\#1): "We trust each other. Her daughter lives with me. We are very involved in each other's personal lives. We will be friends for the rest of our lives."

We found evidence that members did not expect changes in personal or professional context to interrupt relational value or harmony. Continued value generation provides the motivation to perpetuate the collaboration. Responses illustrated how enduring collaborations persist through evolutions in personal and career stages:

I seek his advice to this day on management and finance issues, relationship-type issues. It has expanded greatly over the years. As life changes, when I first met him I was just recently married and now I have children. He has been through that along with work-life balance, children issues. He helps me clarify "Am I thinking about a problem in the right way?" (David, \#2)

Work/Task Responsibility Communal sharing diminishes the importance of individual tasks, and individual contributions are less important so long as the dyad achieves coalition-based goals (Fiske $\&$ Haslam, 2005). Fiske (1992) points out that members of communal sharing groups share the properties of transitivity or categorical equivalence among individuals. Transitivity enables members to substitute in for absent members and perform their partner's role functions. Responses suggested that synergistic situations manifested in unordinary situations requiring members to accept benevolently ephemeral role extensions (Johnston \& Johnson, 1988). Communal sharing involves the coordination of actions (Fiske \& Haslam, 2005), and taking actions on behalf of one's dyad member when necessary to ensure protection of each member's well-being. Pointedly, an indicator of synergy is tacit coordination: the synchronization of members' actions grounded in implicit beliefs about what others in their group would likely do in similar situations (Wittenbaum, Vaughn, \& Strasser, 2002).

We have a high capacity to handle things together when things are thrown at us, where others have not been such partners. He has an illness, so while he was in the hospital I took his position. When he wasn't there I tried to emulate everything he does. (Brad, \#4)

As we developed the presentation of the domains of SCoM detailed here and uncovered the predominant communal sharing model, it became evident 
that collaborative task focused interactions and co-mentoring complement each other in SCoM relational interactions. Respondents' accounts revealed that SCoM emerges when dyadic synergistic characteristics and dyadic comentoring characteristics are both present in a developmental relationship, and when synergy is realized through dyad member interactions that result in combinative accomplishments. We present one example from the interviews to present the elements that appear to characterize a comprehensive definition of SCoM:

I worked directly for him for 12 years ... now working for two different companies. We talk frequently. Unless there is a specific situation that he or I might want to talk to each other about, we probably stay in touch one time a week. Most times the conversations encompass both personal and professional topics. Today, we get together for lunch once every couple of months. It has lasted so many years, and we have been through so many different stages of ... building of the company, many different economic times, you just build on those and it just lasts. It's something that's evolved from a relationship ... working for him as a consultant and then in employment working for him for many years. Now that I don't work with him, the mentor relationship has evolved over the years. It is satisfying that the relationship is strong today after so many years. (Matthew, \#2)

Thus, we offer the following definition of synergistic co-mentoring (SCoM): a dyadic, synergistic, developmental relationship, in which mutually supportive co-mentors collaborate as an enduring unit to accomplish collective goals.

\section{Discussion}

The present research offers a clear description of the dyadic synergistic characteristics and dyadic co-mentoring characteristics that comprise SCoM. We align our contributions in presenting the implications for theory and practice in the sections below according to Suddaby's (2010) prescribed framework for construct clarity, composed of four critical elements to the accumulation of knowledge: definition clarity, relationships among related constructs, logical consistency, and scope. In implications for theory, we advance developmental relationships theory and research by clarifying the language of SCoM, highlighting inconsistencies across the multiple extant definitions and descriptions of synergy within mentoring. SCoM enhances research on the related construct of relational mentoring by introducing a theory of coordination and collaboration, while expanding perspectives on fluid expertise and partners' role boundaries. In implications for research, we communicate how our findings are consistent with - and broaden - research that integrates the theory of social relations with mentoring schema. In practical implications, we suggest boundary conditions for SCoM in terms of developmental network structure 
and content and career development. We end by making qualitative and quantitative study recommendations to advance research based on our findings.

\section{Implications for Theory}

Defining Synergistic Co-mentoring Above, we presented a concise definition of SCoM, presented a set of terms to build a common language of key features that distinguish SCoM, and revealed the intra-relational context that supports SCoM. Prior definitions of synergistic mentoring are imprecise and use similar terms for different concepts. Irby asserts that "deliberate mentoring of synergy must occur for there to be synergistic mentoring", and a mentor "initially establishes the synergy. ... To mentor synergy means movement initiated by the mentor as the leader in the mentoring process" (Irby, 2010, p. 175). Our research contradicts Irby's assertion, as SCoM does not involve active mentoring of synergy. We reveal that synergistic potential is present in dyads exhibiting dyadic synergistic qualities and processes, and that synergy is realized in SCoM when task-focused interactions generate performance gains beyond individual potential.

Our definition extends the foundational work on collaboration in mentoring in important ways. Mullen's (2000) reporting of co-mentoring makes no mention of mentoring career or psychosocial support, meaning co-mentoring as defined therein may be a misnomer for collaborative coaching at the group level, involving skill development in context-specific specialized content areas (Garvey, 2004). In contrast, the definition of SCoM offered here is grounded in descriptive data and offers a baseline for building theory upon this research. We elaborate examples of SCoM dyad members co-developing one another by providing an array of both career and psychosocial subfunctions. Finally, the goal of co-mentoring in partnership support groups is to build support groups for specific research projects, whereas we offer evidence that SCoM occurs in a variety of contexts and produces myriad types of output.

Relational Mentoring In this section, we distinguish SCoM from relational mentoring; while related constructs, it is important to recognize their conceptual distinctions. Fletcher and Ragins (2007) use relational cultural theory as conceptual foundations to explain mentor and protégé selves-inrelation to one another. Theorizing on relational mentoring accounts for the possibility of "an interdependent and generative developmental relationship that promotes mutual growth, learning, and development within the career context" (Ragins \& Verbos, 2007, p. 96) but does not address synergistic potential within dyads.

The context in which developmental relationships operate has changed as "work in organizations has become much more relational, interdependent, and collaborative in nature" (Parise, 2007, p. 360). In our view, SCoM is a response to the way work gets done in the context of multidirectional careers, which has caused a shift toward collaboration and coordination among individuals with cross-domain expertise. Introducing Bruns's (2013) theory of coordination and 
collaboration to research on co-mentoring extends relational mentoring theory (Ragins, 2012) by expressing different directionality and interaction patterns of support flow than previously conceptualized. Synergistic qualities and processes offer an avenue for increased generative capacity (Ragins \& Verbos, 2007), not only of individuals but also for dyads, while developmental qualities and processes involve mutuality juxtaposed to mere reciprocity.

Our findings with respect to SCOM are limited to the sample studied and do not replace established mentoring career and psychosocial support functions and subfunctions, nor supplant the dimensions of relational mentoring. Current descriptions of informal and formal mentors, peers, coaches, and other developmental relationship types (Clutterbuck, 2004) do not explicitly address the potential for, and realization of, synergy between mentors and protégés. We found that in SCoM dyads, rather than protégé-centric career support, dyad members coordinate with and collaborate on projects and engage in fluid expertise. This is contrasted with offering challenging tasks to a protégé. In the SCoM dyads we studied, members set goals with one another as opposed to a mentor setting goals for the protégé, and members grow with one another as opposed to a mentor monitoring protégé progress. Our findings suggest that in SCoM dyads, rather than protégé-centric psychosocial support, dyad members provide mutual personal and professional support and collaborative development. This is contrasted with unidirectional counseling provided to a protégé. Our findings suggest that in SCoM, members coalesce, sharing goal responsibility; members are inducible to one another. This is contrasted with a mentor providing unidirectional role-modeling for a protégé.

\section{Implications for Research}

Theory of Social Relations and Relational Schema In this section, we demonstrate the logical consistency of integrating theory of social relations to the overall conceptual elaboration of SCoM. Our study shows how approaching relationships communally allows qualities of expert knowledge to become fluid between dyad members. In our sample of SCoM dyads, co-mentoring development occurred when mutual sharing between dyad members and inducibility involved collaborative development and knowledge generation. By revealing communal sharing as a model of social relations that accompanies synergistic qualities and processes and developmental qualities and processes, we add a dyadic level of analysis that builds on the Cotton and Shen (2013) study of how social relations shape the effectiveness of different types of developmental relationships.

\section{Implications for Practice}

Building on the work of McCauley (2005), who described mentoring as a tool for HRD, we help HRDPs understand how to capitalize on SCoM for achieving two main HRD objectives: training and development, and career development. 
Training and Development Our findings have implications for transferring learning gained in a training setting to its application as new knowledge, skills, and abilities - a major objective and obstacle for HRD initiatives (Hegstad \& Wentling, 2004). According to Larson (2010), transactive memory is a foundational mechanism for performance gains in learning, as group learning benefits subsequent performance gains on tasks where the learning occurred.

HRDP might consider creating training interventions to stimulate synergy within developmental dyads by embracing the expertise diversity that has changed the way employees learn, share knowledge, and collaborate through coordinating tasks (Bruns, 2013; Parise, 2007). Our results suggest that knowledge generation in SCoM results from process gains (Wegner et al., 1985), which occurs when collaborative efforts lead to greater and more novel idea generation and problem-solving capabilities. HRDPs may guide dyad members toward processes of role inversion, collaboration and coordination, and distribution of resources that engage dyad members in discovering expertise complementarity, encouraging coalition goal responsibility. Support for this approach is illustrated in a study of dyadic work teams that demonstrated task interdependence and cooperative goal interdependence, and innovation support predicted transactive memory, which in turn improved group performance ratings by leaders or managers (Zhang, Hempel, Han, \& Tjosvold, 2007).

HRDPs should train dyad members together on developmental processes of fluid expertise, collaborative development, and knowledge generation, using SCoM as a conduit for performance gains. Olsson, Juslin, and Olsson (2006) found that dyad members' collective performance on judgment and memory tasks significantly improved when they trained and studied together, indicating that a learning process of experiencing training together created dyad-specific knowledge beyond both members' individual capacity. The present research equips HRDPs with knowledge of the developmental qualities and processes and demonstrates how sharing one's cognitive space with a co-mentor (i.e., such that dyad members jointly experience the same training time, learning space, and content) makes development more impactful for both members and lends itself to producing learning alliances (Clutterbuck, 1998). Respondents indicated that when generating knowledge, members were just as likely to enact the role of mentor as they were protégé. Thus, training and development might include facilitating bidirectional dialogue about the qualities of expert-level knowledge of dyad members, promoting integrative strategies to offer mutual support (Fusaroli et al., 2014), and encouraging dyad members to be open to inducibility through sharing differentiated concepts.

Career Development We make three recommendations for HRDPs regarding career development and developmental networks: 
1. Help employees understand their developmental network and the gap in their network that may exist if none of the employee's current relationships represent SCoM. Understanding a network approach to development suggests that the dynamic interplay of network size, density, diversity, multiplexity, reachability, and tie strength fulfill an employee's unique set of developmental needs (Garavan et al., 2012) and influence career development (Dobrow, Chandler, Murphy, \& Kram, 2012). Developmental network content conveys the presence of career and psychosocial support subfunctions available within a focal protégés developmental network. SCOM dyads appear to consist of highly interdependent mentors that provided numerous career and psychosocial support subfunctions to each other in a professional context (Cotton et al., 2011). Consequently, SCoM dyads reported strong ties, which refer to high affect, reciprocity, and communication frequency between co-mentors. No SCoM dyad comprised dyad members who provided skills development in only one specific area, or members who exchanged single-instance developmental interactions. This implies boundary conditions for HRDPs on what types of individuals within the developmental network likely foster SCoM relationships.

2. Evaluate synergistic and co-mentoring potential between dyad members (see inventory: Mullen, 2000), to help employees identify whom to look for to seek SCoM. Network diversity refers to the array of contexts from which a protégé receives developmental support (e.g., career communities, professional settings, educational institutions). As shown in Table 3, SCoM dyads emerged from different types of reporting relationships and organizational direction (two supervisory, three nonsupervisory, three peer), as well as structure (one formal and seven informal). Those individuals labeled as mentors in our coding held higher organizational positions at the time of relationship initiation in $75 \%$ of dyads. These patterns suggest that organizational distance/direction and relationship structure were not differentiating factors in the emergence of SCoM. None of the SCoM dyads were composed of spouses, parents, or personal friends, as it is unlikely any of these roles possess the capacity to engage in the type of career-related interactions in a professional context that facilitate the processes requisite of synergy. Considering our results, SCoM partners will likely consist of CEO/entrepreneur, work teammate, manager, and other individuals from professional arenas.

3. Rock and Garavan (2006) noted how organizational support for mentoring is an important predictor of mentoring. One way to build executive support is to align HRD objectives with strategic organizational development (Anderson, 2009), e.g., implementing mentoring as a lowcost high-impact investment for talent development (Chandler, Hall, \& Kram, 2010). HRD should create opportunities for employees to learn how to apply the foundational elements and features of SCoM as a best practices model around which to recreate other relationships within their 
developmental networks. The quotes below illustrate how SCoM might be perpetuated organically at little cost to the organization for the spread of best practices:

I use my relationship with Matthew as part of my mentoring to others, other younger folks who're, I guess really doesn't matter on age, but I talk about how that relationship has enriched my career and furthered Matthew's career and I use him as an example quite frequently. (Brandon, \#2)

Tara ... was a trainer, and so she would talk about her relationship with me while she was in front of other training classes. We were discussing with management that there needs to be a mentor-mentee relationship in this industry really as a whole and certainly in this company.... So we gave that presentation to the board together. (Emily, \#1)

Tara (\#1) confirms: Emily is the most notable person I have been in mentorship with. I use her as an example when I do my trainings of other people.

\section{Limitations}

Sample Size and Sample Characteristics Sample size is frequently a limitation when making inferences from qualitative data, and ours is no exception. We acknowledge our inability to draw empirical inferences from the demographic characteristics of respondents in our sample, and offer that our results align with the mixed findings in research on surface-level diversity within developmental dyads, for example, same versus cross-gender (O'Brien, Biga, Kessler, \& Allen, 2010), same versus cross-race (Turban, Dougherty, \& Lee, 2002), and culture effects (Clutterbuck $\&$ Ragins, 2002). Our data suggest a connection between diversity as factors in the emergence of SCoM. As shown in Table 3, at the time of relational initiation, mentors were older by 6.7 years and protégés were older by 4.5 years in SCoM dyads compared to non-SCoM dyads. The average difference between these groups was greater by about 2 years. Seven of eight SCoM dyads were same gender. Ethnicity does not seem to be a differentiating factor, as there were about as many same ethnicity as cross-ethnic dyads. Thus, age may play a significant role in the development of SCoM, whereas gender and culture may not. This suggests a need to further consider how deep-level diversity (skills, knowledge, abilities; Larson, 2007) contributes to synergistic characteristics and co-mentoring characteristics.

Time Frame, Synergy, and Social Relations Our study was limited by the cross-sectional nature of the interview process, which prohibited us from observing the emergence of synergy in real time and potential changes in social relations over time. As Larson (2007) notes, synergy takes time to emerge, and group interaction is not a necessarily a stimulus for performance gains. In the first integration of Fiske's (1992) theory of social relations into developmental 
relationship research, Cotton and Shen (2013) showed that mentors and protégés approach each relationship using the four different models of social relations, which varies per role and type of relationship in operation (or expected) at initiation. People assign a model to each relationship, but fluidly switch among the remaining models according to context and situational demands. This suggests that the dominant model of social relations may change over time as the nature of the relationship evolves. Ours is the first study that attempts to evaluate intersubjectivity between dyad members regarding which model of social relations was in operandi. Our results provide support for intersubjective agreement of a dominant communal sharing model in SCoM dyads, and that applying the same model of social relations played a part in SCoM. Yet we cannot infer causality from our data. Longitudinal research designs would enable researchers to observe developmental dyads across the stages of their relationship. Researchers could then determine if SCoM dyad members entered the relationship using a communal sharing model, or whether partners shifted from some other model into communal sharing. Further, scholars might also find examples where communal sharing was not the dominant model of social relations but SCoM emerged, and where communal sharing was dominant but SCoM did not emerge.

Organizational Development One limitation of our study was that we did not collect organizational-level data. Allen, Smith, Mael, O'Shea, and Eby (2009) revealed indirect effects of organization-level mentoring on organizational performance through organization-level job satisfaction, organizational citizenship behaviors, and organizational learning. In the present research, several respondents provided insights highlighting a potential link between SCoM synergistic performance gains and organizational development, for example, project achievement experiences (dyads 2, 3, and 7), increasing performance on shared goals (dyads 1 and 8), and increasing interdepartmental efficiencies (dyad 5). These suggested links stimulate future research that explores whether the effects of such accomplishments extend beyond the boundaries of the dyad and make measurable contributions to the organization.

\section{Future Directions}

Qualitative Research Because the study of SCoM is embryonic, future inquiry should be directed toward cultivating a more robust understanding of SCoM. Qualitative research may be the most appropriate starting point for discovery, as information-rich interviews and observation are a genesis for revealing phenomenon intricacies. Future research could expand the generalizability of the current study by implementing a research design in which mentoring dyads are observed in a variety of settings as they naturally occur within organizations. Questions for understanding SCoM include: What additional synergistic qualities and processes and developmental qualities and processes exist within developmental dyads? In SCoM, the nature of 
engaging in collective actions that drive combinative accomplishments necessarily involves collaboration and coordination; activities not considered in the most current definitions of career and psychosocial subfunctions. Thus, needed is an analysis of how unique qualities and process in SCoM might combine in such a way that manifests in yet-to-be-discovered types of mentoring support.

Do individuals seek out developmental partners on the basis of synergistic qualities and the potential for collaboration? Given our findings regarding the effects of complementarity, we offer a divergent view from prior studies that use attraction similarity theory (Ibarra, 1992) to suggest that individuals seek out like others to build relationships with. Homophily leads to redundant information, reduces network diversity (Higgins \& Kram, 2001), and likely prohibits emergence of both synergistic and co-mentoring characteristics. Research is needed to understand whether synergistic potential and the opportunity to develop alongside one's partner factor in a decision to initiate a relationship. Thus, we encourage mentoring studies that incorporate mutuality perspectives and methodologies that examine the dyad through the lens of both partners (Dobrow et al., 2012).

Empirical Research We add to calls to open the black box around dyadic mentoring processes and interactions (Chandler et al., 2010). Dyads with synergistic qualities and co-mentoring qualities may never realize synergy or engage in co-mentoring when processes are left inert. Research questions for future studies might include: How do qualities instigate processes? In what order does such instigation occur; that is, do dyadic partners first engage in synergistic endeavors or developmental processes? Answering these questions requires the development of measures to operationalize SCoM, testing for multidimensionality, exploring the nomological network in which it operates, and examining potential mediating and moderating mechanisms in SCoM, as described above.

\section{Conclusion}

The current qualitative study integrated the literatures on developmental relationships and theory of social relations to develop an understanding of SCoM and its potential benefits to HRD. Interview data revealed that synergistic dyadic qualities and processes and developmental dyadic qualities and processes were present in our sample of matched dyads when SCoM emerged. SCoM emerged when dyadic synergistic characteristics and dyadic comentoring characteristics were both present in the dyad; synergy was realized through dyad member interactions that result in combinative accomplishments, and when communal sharing was the predominant relational approach applied by members. We encourage future research to further explore theoretical models that describe the development of this phenomenon, and how SCoM can be applied to HRD. 


\section{References}

Allen, T. D., Smith, M. A., Mael, F. A., O'Shea, P. G., \& Eby, L. T. (2009). Organization-level mentoring and organizational performance within substance abuse centers. Journal of Management, 35, 1113-1128.

Anderson, V. (2009). Desperately seeking alignment: reflections of senior line managers and HRD executives. Human Resource Development International, 12, 263-277.

Bruns, H. C. (2013). Working alone together: Coordination in collaboration across domains of expertise. Academy of Management Journal, 56, 62-83.

Bunderson, J. S., \& Sutcliffe, K. M. (2002). Comparing alternative conceptualizations of functional diversity in management teams: Process and performance effects. Academy of Management Journal, 45, 875-893.

Chandler, D. E., Hall, D. T., \& Kram, K. E. (2010). A developmental network \& relational savvy approach to talent development: A low-cost alternative. Organizational Dynamics, 39, 48-56.

Chase, W. G., \& Simon, H. A. (1973). Perception in chess. Cognitive Psychology, 4(1), 55-81.

Clutterbuck, D. (1998). Learning alliances: Tapping into talent. London, England: CIPD House.

Clutterbuck, D. (2004). Everyone needs a mentor: Fostering talent in your organization. London, England: CIPD House.

Clutterbuck, D., \& Ragins, B. R. (2002). Mentoring and diversity: An international perspective. Woburn, MA: Butterworth-Heinemann.

Cohen, D., Whitmyre, J. W., \& Funk, D. W. (1960). Effects of group cohesion and training upon creative thinking. Journal of Applied Psychology, 44, 319-322.

Corbin, J., \& Strauss, A. (2014). Basics of qualitative research: Techniques and procedures for developing grounded theory. Thousand Oaks, CA: Sage.

Cotton, R. D., \& Shen, Y. (2013). The company you keep: The relational models and support expectations of key developer relationships. Career Development International, 18, 328-356.

Cotton, R. D., Shen, Y., \& Livne-Tarandach, R. (2011). On becoming extraordinary: The content and structure of the developmental networks of Major League Baseball Hall of Famers. Academy of Management Journal, 54, 15-46.

Cummings, J. N., \& Kiesler, S. (2007). Coordination costs and project outcomes in multi-university collaborations. Research Policy, 36, 1620-1634.

D'Abate, C. P., Eddy, E. R., \& Tannenbaum, S. I. (2003). What's in a name? A literature-based approach to understanding mentoring, coaching, and other constructs that describe developmental interactions. Human Resource Development Review, 2, 360-384.

Deutsch, M. (2003). Cooperation and conflict: A personal perspective on the history of the social psychology study of conflict resolution. In M. West, D. Tjosvold, \& K. Smith (Eds.), International handbook of organizational teamwork and cooperative working (pp. 9-44). New York, NY: Wiley.

Dobrow, S. R., Chandler, D. E., Murphy, W. M., \& Kram, K. E. (2012). A review of developmental networks incorporating a mutuality perspective. Journal of Management, 38, 210-242.

Eby, L. T., Allen, T. D., Hoffman, B. J., Baranik, L. E., Sauer, J. B., Baldwin, S., ... Evans, S. C. (2013). An interdisciplinary meta-analysis of the potential antecedents, correlates, and consequences of protégé perceptions of mentoring. Psychological Bulletin, 139, 441-476.

Faraj, S., \& Sproull, L. (2000). Coordinating expertise in software development teams. Management Science, 46, 1554-1568.

Fiske, A. P. (1992). The four elementary forms of sociality: Framework for a unified theory of social relations. Psychological Review, 99, 689-723.

Fiske, A. P., \& Haslam, N. (2005). The four basic social bonds: Structures for coordinating interaction. In Mark W. Baldwin (Ed.), Interpersonal cognition (pp. 267-298). New York, NY: Guilford Press.

Fletcher, J. K., \& Ragins, B. R. (2007). Stone center relational cultural theory: A window on relational mentoring. In B. R. Ragins \& K. E. Kram (Eds.), The handbook of mentoring at work: Theory, research and practice (pp. 373-399). Thousand Oaks, CA: Sage. 
Fusaroli, R., Rączaszek-Leonardi, J., \& Tylén, K. (2014). Dialog as interpersonal synergy. New Ideas in Psychology, 32, 147-157.

Garavan, T. N., Carbery, R., \& Rock, A. (2012). Mapping talent development: Definition, scope and architecture. European Journal of Training and Development, 36(1), 5-24.

Garvey, B. (2004). The mentoring/counseling/coaching debate: Call a rose by any other name and perhaps it's a bramble? Development and Learning in Organizations: An International Journal, $18(2), 6-8$.

Garvey, B., \& Alred, G. (2001). Mentoring and the tolerance of complexity. Futures, 33, 519-530.

Greengard, S. (2002). Moving forward with reverse mentoring. Workforce, 81(3), 15.

Hegstad, C. D. (1999). Formal mentoring as a strategy for human resource development: A review of research. Human Resource Development Quarterly, 10, 383-390.

Hegstad, C. D., \& Wentling, R. M. (2004). The development and maintenance of exemplary formal mentoring programs in Fortune 500 companies. Human Resource Development Quarterly, 15, 421-448.

Henry, R. A. (1993). Group judgment accuracy: Reliability and validity of post discussion confidence judgments. Organizational Behavior and Human Decision Processes, 56, 11-27.

Higgins, M. C., \& Kram, K. E. (2001). Reconceptualizing mentoring at work: A developmental network perspective. Academy of Management Review, 26, 264-288.

Ibarra, H. (1992). Homophily and differential returns: Sex differences in network structure and access in an advertising firm. Administrative Science Quarterly, 37, 422-447.

Ickes, W., \& Dugosh, J. W. (2000). An intersubjective perspective on social cognition and aging. Basic and Applied Social Psychology, 22, 157-167.

Irby, B. J. (2012). Editor's overview: From mentoring synergy to synergistic mentoring. Mentoring E Tutoring: Partnership in Learning, 20, 175-179.

Johnston, D. M., \& Johnson, N. R. (1988). Role extension in disaster: Employee behavior at the Beverly Hills Supper Club fire. Sociological Focus, 22, 39-51.

Larson, J. R. Jr. (2007). Deep diversity and strong synergy: Modeling the impact of variability in members' problem-solving strategies on group problem-solving performance. Small Group Research, 38, 413-436.

Larson, J. R. Jr. (2010). In search of synergy in small group performance. New York, NY: Psychology Press.

Laughlin, P. R., Bonner, B. L., \& Miner, A. G. (2002). Groups perform better than the best individuals on letters-to-numbers problems. Organizational Behavior and Human Decision Processes, $88,605-620$.

McCauley, C. D. (2005). The mentoring tool. Advances in Developing Human Resources, 7, 443-445.

McLagan, P. (1989). Models for HRD practice. Alexandria, VA: American Society for Training and Development.

Merriam, S. (2009). Qualitative research: A guide to design and implementation. San Francisco, CA: Jossey Bass.

Mullen, C. A. (2000). Constructing co-mentoring partnerships: Walkways we must travel. Theory into Practice, 39(1), 4-11.

Mullen, C. A., \& Lick, D. W. (1999). New directions in mentoring: Creating a culture of synergy. London, England: Falmer Press.

O'Brien, K. E., Biga, A., Kessler, S. R., \& Allen, T. D. (2010). A meta-analytic investigation of gender differences in mentoring. Journal of Management, 36, 537-554.

Olsson, A. C., Juslin, P., \& Olsson, H. (2006). Multiple cue judgment in individual and dyadic learning. Journal of Experimental Social Psychology, 42, 40-56.

Parise, S. (2007). Knowledge management and human resource development: An application in social network analysis methods. Advances in Developing Human Resources, 9, 359-383.

Ragins, B. R. (2012). Relational mentoring: A positive approach to mentoring at work. In Cameron, K., \& Spreitzer, G. (Eds.), The handbook of positive organizational scholarship (pp. 519538). New York, NY: Oxford University Press. 
Ragins, B. R. (2016). From the ordinary to the extraordinary: High-quality mentoring relationships at work. Organizational Dynamics, 45, 228-244.

Ragins, B. R., \& Verbos, A. K. (2007). Positive relationships in action: Relational mentoring and mentoring schemas in the workplace. In J. Dutton, $\&$ B. R. Ragins (Eds.), Exploring positive relationships at work: Building a theoretical and research foundation (pp. 91-116). Mahwah, NJ: Lawrence Erlbaum.

Robinson, O. C. (2014). Sampling in interview-based qualitative research: A theoretical and practical guide. Qualitative Research in Psychology, 11(1), 25-41.

Rocco, T. S. (2003). Shaping the future: Writing up the method on qualitative studies. Human Resource Development Quarterly, 14, 343-349.

Rocco, T. S. (2010). Criteria for evaluating qualitative studies. Human Resource Development International, 13, 375-378.

Rock, A. D., \& Garavan, T. N. (2006). Reconceptualizing developmental relationships. Human Resource Development Review, 5, 330-354.

Sherman, J. D. (2002). Leader role inversion as a corollary to leader-member exchange. Group $\&$ Organization Management, 27, 245-271.

Stevenson, W. B., Pearce, J. L., \& Porter, L. W. (1985). The concept of "coalition" in organization theory and research. Academy of Management Review, 10, 256-268.

Suddaby, R. (2010). Editor's comments: Construct clarity in theories of management and organization. Academy of Management Review, 35, 346-357.

Thurston, P. W., D’Abate, C. P., \& Eddy, E. R. (2012). Mentoring as an HRD approach: Effects on employee attitudes and contributions independent of core self-evaluation. Human Resource Development Quarterly, 23, 139-165.

Turban, D. B., Dougherty, T. W., \& Lee, F. K. (2002). Gender, race, and perceived similarity effects in developmental relationships: The moderating role of relationship duration. Journal of Vocational Behavior, 61, 240-262.

Ueno, K., \& Adams, R.G. (2006). Adult friendship: A decade review. In P. Noller \& J. Feeney (Eds.), Close Relationships (pp. 151-169). East Sussex, England: Psychology Press.

Wegner, D. M., Giuliano, T., \& Hertel, P. T. (1985). Cognitive interdependence in close relationships. In W. Ickes (Ed.), Compatible and incompatible relationships (pp. 253-276). New York, NY: Springer-Verlag.

Williams, E. A., Scandura, T. A., \& Gavin, M. (2009). Understanding team-level career mentoring by leaders and its effects on team-source learning: The effects of intra-group processes. Human Relations, 62, 1635-1666.

Wittenbaum, G. M., Vaughan, S. I., \& Strasser, G. (2002). Coordination in task-performing groups. In R. S. Tindale, L. Heath, J. Edwards, E. J. Posavac, F. B. Bryant, Y. Suarez-Blacazer, E. Henderson-King, \& J. Myers (Eds.), Theory and research on small groups (pp. 177-204). New York, NY: Springer-Verlag.

Zhang, Z. X., Hempel, P. S., Han, Y. L., \& Tjosvold, D. (2007). Transactive memory system links work team characteristics and performance. Journal of Applied Psychology, 92, 1722-1730.

Bryan J. Deptula, MBA, PhD, is an assistant professor of Leadership and Management at H. Wayne Huizenga College of Business E Entrepreneurship in Fort Lauderdale, Florida.

Ethlyn Anne Williams, PhD, is an assistant professor at Florida Atlantic University College of Business in Boca Raton, Florida.

\section{Corresponding author:}

Bryan Deptula can be contacted at bdeptula@nova.edu 